\title{
Amazonian Foods: Açaí, Camu-Camu, Cubiu and Pupunha
}

\section{ISSN: 2640-9208}

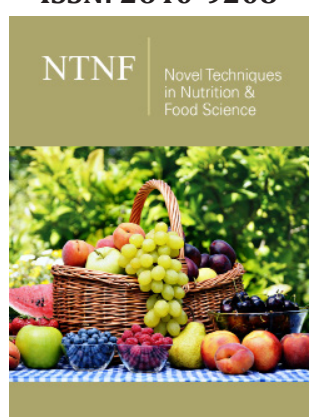

*Corresponding author: Jaime Paiva Lopes Aguiar, National Institute for Research in the Amazon, Laboratory of Physical Chemistry of Food (LFQA) Manaus, AM,Brazil.

Email: jaguiar@inpa.gov.br

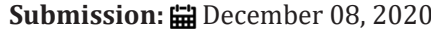

Published: 留December 16, 2020

Volume 5 - Issue 3

How to cite this article: Jaime Paiva Lopes Aguiar, Francisca das Chagas do Amaral Souza. Amazonian Foods: Açaí, CamuСamu, Cubiu and Pupunha. Nov Tech Nutri Food Sci. 5(3). NTNF. 000614. 2020. DOI: 10.31031/NTNF.2020.05.000614

Copyright@ Jaime Paiva Lopes Aguiar This article is distributed under the terms of the Creative Commons Attribution 4.0 International License, which permits unrestricted use and redistribution provided that the original author and source are credited.

\author{
Jaime Paiva Lopes Aguiar* and Francisca das Chagas do Amaral Souza
}

National Institute for Research in the Amazon, Brazil

Keywords: Fruits of the Amazon; Products with added value, Food and nutritional security

\section{Opinion}

What is the nutritional value of typical Amazonian products such as açaí wine (Euterpe precatoria Mart.), Camu-camu (Myrciaria dubia (Kunth) McVaugh), cubiu (Solanum sessiliflorum Dunal) and peach palm flour (Bactris gasipaes Kunth).? Can these foods be used to prevent common diseases in the Amazon, such as energy-protein malnutrition, iron deficiency anemia and hypovitaminosis A? If not as a preventive way, can these foods be used to minimize these public health problems still registered in different population groups in the Amazon region?

For these questions, a group of researchers from the National Institute for Research in the Amazon (INPA) is looking for answers. The work mainly targets the school population and also aims to identify the technological and nutritional agronomic potential of the mentioned plant species. An essential part of the research is the analysis of the chemical composition of the fruit and the evaluation of products and diet. The impact assessment regarding the use of pupunha flour as a source of pro-vitamin A has as a sample group voluntary preschooler aged 2 to 7 years old, in a total of 90 children, divided into three groups of 30: an experimental group (which received the product extracted from Amazonian food), a control group, which received vitamin $\mathrm{A}$ and the placebo group, thus constituting the preventive evaluation. It is concluded that pupunha flour is an excellent source of energy, fiber, oil, and is highly recommended for the prevention of hypovitainosis A.

The assessment of the impact of açaí "wine" on preschoolers was done by studying the hemoglobin concentrations in the blood. For this purpose, a sample of 60 children aged 2 to 6 years was selected, divided into three groups of 20: an experimental group (which received iron from açai), a control group, which received iron and a placebo group, constituting thus the evaluation in the preventive form. The results showed that açaí juice is an energy source reflecting the weight gain of the children studied. As it is an energy source it can contribute to the reduction of Protein Energy Malnutrition. The evaluation of the hypoglycemic action of cubiu is initially tested in diabetic rats, for a period of 45 days. The information generated by this project allows the expansion of the food composition table at regional and national level, as well as the elaboration of a national database of regional products with potential in the domestic and foreign markets.

The nutritional diagnosis of population groups answers questions about the prevalence and extent of energy-protein malnutrition, iron deficiency anemia and hypovitaminosis A in the Amazon region and consequently supports the direction of public policies in several sectors, particularly health. The minimization of nutritional deficiencies in the region using potentially nutritious regional foods will reflect in the improvement of the socio-economic- 
cultural and environmental standard of low-income populations and in the quality of life.

The additional advantage of working with children is also in their assimilation power, since, together with the projects, nutritional education is always a work of great scope. With this research, we hope to contribute to the rescue of healthy eating habits and practices, through the insertion of fruits from Amazonian biodiversity and products with added value, in addition to promoting health, it can contribute to reinforce food sovereignty and assist in the preservation of cultural identity of the region and Brazil. In the economic and social aspect, the availability of technically viable products will favor the timidity of the market, combined with a public policy involving the entire production chain. It is expected to contribute to healthy and varied food, public policies, income generation, social inclusion, food and nutritional security and improving the quality of life of the population in the Amazon.

\section{Conflicts of Interest}

The authors declare to have no conflict of interest about the publication of this paper. 